\title{
Anfíbios e répteis do Parque Nacional da Serra da Bodoquena, Mato Grosso do Sul, Brasil
}

Masao Uetanabaro' ${ }^{1}$, Franco Leandro Souza ${ }^{1,5}$, Paulo Landgref Filho ${ }^{2}$, Arlindo Figueira Beda ${ }^{3}$ \& Reuber Albuquerque Brandão ${ }^{4}$

Biota Neotropica $v 7$ (n3) - http://www.biotaneotropica.org.br/v7n3/pt/abstract?inventory+bn01207032007

\author{
Recebido em 10/06/07 \\ Versão Reformulada recebida em 30/08/07 \\ Publicado em 06/09/07
}

${ }^{1}$ Departamento de Biologia, Centro de Ciências Biológicas e da Saúde,

Universidade Federal de Mato Grosso do Sul,

Av. Costa e Silva, s/n, Cidade Universitária, CEP 79070-900, Campo Grande, MS, Brasil,

e-mail: masao.uetanabaro@gmail.com

${ }^{2}$ Programa de Pós-Graduação em Ecologia e Conservação, Centro de Ciências Biológicas e da Saúde, Universidade Federal de Mato Grosso do Sul, CEP 79070-900, Campo Grande, MS, Brasil, e-mail: paulograf@yahoo.com.br

${ }^{3}$ Campus de Aquidauana, Universidade Federal de Mato Grosso do Sul, Praça N. S. Conceição, 163, CEP 79200-000, Aquidauana, MS, Brasil, e-mail: afbeda@ gmail.com

${ }^{4}$ Departamento de Engenharia Florestal - EFL, Faculdade de Tecnologia, Universidade de Brasília,

CEP 70910-900,Brasília, DF, Brasil, e-mail: reuberbrandao@yahoo.com.br

${ }^{5}$ Autor para correspondência: Franco Leandro Souza, e-mail: flsouza@nin.ufms.br

\begin{abstract}
Uetanabaro, M, Souza, F.L., Landgref Filho, P., Beda, A.F. \& Brandão, R.A. Amphibians and reptiles of the Serra da Bodoquena National Park, Mato Grosso do Sul, central Brazil. Biota Neotrop. Sep/Dez 2007 vol. 7, no. 3 http://www.biotaneotropica.org.br/v7n3/pt/abstract?inventory+bn01207032007. ISSN 1676-0603.

The State of Mato Grosso do Sul, central Brazil, is located in the center of the broad South American opendry diagonal areas. This region harbors a great diversity of amphibians and reptiles, with some endemic species. Despite such biogeographical scenario, biodiversity of this region is poorly known at local scales. Dry forests are important physiognomies in Mato Grosso do Sul and represent an important landscape element at Serra da Bodoquena, resulting in local characteristics that require biodiversity surveys. There are few and punctual information on the herpetofauna from the Serra da Bodoquena National Park and they suggest a similarity with the Cerrado herpetofauna. The present study represents the first record of the herpetofauna from the Serra da Bodoquena National Park and adjacent areas. Samples were conducted in pristine and disturbed areas in two distinct climatic periods, covering both rainy and dry seasons, by means of active search limited by time as well as opportunistic records. Data on the herpetofauna of the Caatinga, Cerrado, and Chaco biomes were compiled and compared with the species sampled in the present study. We registered 63 species, including 38 amphibians and 25 reptiles. Several species were associated to particular habitats, such as gallery forests or rocky outcrops. The herpetofauna from the Serra da Bodoquena National Park showed a greater similarity with that of the Cerrado, probably because the area is inserted in this biome. Considering the habitat diversity found at Serra da Bodoquena, the number of species must increase with other surveys in the area. Natural history and ecological studies on amphibian and reptiles of the Serra da Bodoquena must be encouraged in order to contribute for the National Park management.

Keywords: Amphibia, Reptile, faunal survey, Serra da Bodoquena National Park.

\section{Resumo}

Uetanabaro, M, Souza, F.L., Landgref Filho, P., Beda, A.F. \& Brandão, R.A. Anfíbios e répteis do Parque Nacional da Serra da Bodoquena, Mato Grosso do Sul, Brasil. Biota Neotrop. Sep/Dez 2007 vol. 7, no. 3 http://www.biotaneotropica.org.br/v7n3/pt/abstract?inventory+bn01207032007. ISSN 1676-0603.

O Estado de Mato Grosso do Sul situa-se na porção mediana da grande diagonal de formações abertas da América do Sul, uma região que abriga uma grande diversidade de anfíbios e répteis, sendo algumas endêmicas. Apesar de sua importância biogeográfica, essa diagonal tem sido pouco considerada em estudos com abrangência regional. Dentre os componentes fitofisionômicos que compõem essa região e cuja representatividade se faz presente no Estado, as matas estacionais deciduais são elementos marcantes na região da Serra da Bodoquena. Devido a peculiaridade desse ambiente, muitas áreas ainda necessitam de uma maior avaliação quanto à sua biodiversidade. Informações sobre a herpetofauna do Parque Nacional da Serra da Bodoquena são escassas e pontuais e sugerem uma semelhança com a fauna de cerrado. Este trabalho apresenta registros da herpetofauna do
\end{abstract}


Parque Nacional da Serra da Bodoquena e regiões de entorno, abrangendo áreas em bom estado de conservação e locais com atividade agropecuária. As amostragens foram realizadas em dois períodos, contemplando as estações seca e chuvosa na região. $\mathrm{O}$ inventário consistiu em busca ativa limitada por tempo, além de registros oportunísticos. Informações sobre a riqueza de espécies da herpetofauna da Caatinga, Cerrado e Chaco foram compiladas da literatura e comparadas com aquela registrada no presente trabalho. Foram registradas 63 espécies, sendo 38 anfíbios e 25 répteis. Muitas das espécies estavam associadas a ambientes particulares, como matas de galeria e afloramentos rochosos. A maior similaridade da herpetofauna do Parque Nacional da Serra da Bodoquena deu-se com aquela encontrada no Cerrado, provavelmente porque a área está inserida nesse bioma. Considerando-se a diversidade de hábitats da área, provavelmente o número de espécies deverá aumentar com a realização de novos inventários na região. Agregar novas informações sobre a herpetofauna da Serra da Bodoquena é fundamental para o plano de manejo do Parque Nacional.

Palavras-chave: anfíbios, répteis, inventário faunístico, Parque Nacional da Serra da Bodoquena.

\section{Introdução}

São registradas para o Brasil 776 espécies de anfíbios (748 Anura, 27 Gymnophiona e uma Urodela) e 641 espécies de répteis (seis Crocodylia, 35 Testudines, 57 anfisbênias, 217 lagartos e 326 serpentes) (SBH 2005a,b). A frequiente descrição de novas espécies a cada ano sugere que essa riqueza pode ser ainda maior. Boa parte dessa biodiversidade está representada nas regiões sob influência do cerrado, o que corresponde a 141 espécies de anfíbios (42 endêmicas), cinco espécies de crocodilianos, dez espécies de quelônios, 16 espécies de anfisbênias (oito endêmicas), 47 espécies de lagartos (12 endêmicas) e 107 espécies de serpentes (11 endêmicas) (Colli et al. 2002, Souza 2005). A complexidade e heterogeneidade encontradas em suas diversas fitofisionomias (Eiten 1972, Coutinho 1978), bem como a influência dos biomas vizinhos, sugerem a existência de padrões de distribuição geográfica das espécies vinculadas a essas formações (Brandão \& Araújo 2001, Colli 2005, Souza 2005).

Nos últimos anos, as fisionomias encontradas no Estado do Mato Grosso do Sul têm sofrido intensa descaracterização devido à ação antrópica, particularmente da atividade agropastoril. Essa intensa modificação ambiental implica em um processo de degradação e fragmentação do ambiente, cujo resultado para a biodiversidade é a redução do tamanho das populações, podendo ocasionar extinções locais (Primack 2002). O Estado do Mato Grosso do Sul engloba áreas que abrangem fitofisionomias típicas do Pantanal, Cerrado e Chaco, tais como brejos, matas estacionais e veredas, com componentes bióticos particulares (Prado \& Gibbs 1993, Spichiger et al. 2004, Morrone 2006), formando um mosaico de ecossistemas, muitas vezes integrados, distribuídos ao longo de um vasto território, proporcionando um imenso campo para estudos de ambientes naturais. O Estado situa-se na porção central da grande área diagonal de formações abertas da América do Sul, que se estende desde a Caatinga no nordeste do Brasil até o Chaco na Argentina, onde ocorrem áreas de contato entre o Pantanal, o Chaco e o Cerrado. A diagonal de áreas abertas abriga uma grande diversidade de anfíbios e répteis, incluindo espécies endêmicas (Bucher 1980, Vanzolini 1988, Cabrera 1995, Duellman 1999, Colli et al. 2002, Souza 2005). Apesar de sua importância biogeográfica, essa diagonal tem sido pouco contemplada com estudos de abrangência regional. Dentre os componentes fisionômicos que compõem essa diagonal e cuja representatividade se faz presente em Mato Grosso do Sul, as matas estacionais (deciduais ou semideciduais; sensu Veloso et al. 1991) exercem um papel chave na distribuição de diversos elementos da fauna e da flora (Prado \& Gibbs 1993, Spichiger et al. 2004, Morrone et al. 2004, Morrone 2006). No entanto, estas formações florestais foram fortemente afetadas por atividades antrópicas, tais como mineração de calcário, exploração madeireira e abertura de pastagens (Miles et al. 2006, Silva et al. 2006).
Dados fitogeográficos sugerem que as matas estacionais possam ter tido uma extensa distribuição geográfica, do norte do Brasil ao sudoeste da Bolívia e norte da Argentina, geralmente associadas a solos mais férteis onde alguns taxa sobressaem-se em afloramentos de áreas elevadas que exibem solo rico em calcário (Prado \& Gibbs 1993), como é o caso da Serra da Bodoquena. Assim como no cerrado, muitas espécies de plantas podem ter suas distribuições geográficas associadas às áreas de ocorrência dessa formação vegetal (Prado \& Gibbs 1993), representando áreas de endemismo potencial. Dada a peculiaridade desse ambiente, muitas localidades ainda necessitam de uma maior avaliação quanto à sua riqueza de fauna e flora. Como uma feição de relevo, de solo fértil e coberta, em sua maior parte, por matas semideciduais, trata-se de uma formação particular, isolada pelo Cerrado, o que pode levar ao isolamento de populações e especiações.

O Parque Nacional da Serra da Bodoquena foi criado pelo Decreto de 21 de setembro de 2000, com os objetivos de preservar ecossistemas naturais de grande relevância ecológica e beleza cênica, possibilitar a realização de pesquisas científicas, de atividades de educação ambiental e recreação em contato com a natureza e de turismo ecológico. Desde então, não foram realizados inventários de biodiversidade na área. Informações sobre a herpetofauna do Parque Nacional da Serra da Bodoquena são escassas e pontuais (p. ex. Strüssmann et al. 2000, Rodrigues 2001, Ghedini 2004, Rodrigues et al. 2003, 2004, 2005) e, aparentemente, sugerem uma semelhança com a fauna de cerrado. Este trabalho apresenta uma listagem preliminar da herpetofauna do Parque Nacional da Serra da Bodoquena, amostrando a fauna em áreas com bom estado de conservação e também em locais com notória atividade agropastoril. Esse enfoque em áreas de entorno e no efeito do uso da terra sobre a herpetofauna é particularmente relevante, pois planos de manejo, zoneamentos ecológicos e monitoramentos devem considerar os efeitos do uso de tais áreas sobre a unidade de conservação.

\section{Material e Métodos}

O Parque Nacional da Serra da Bodoquena, PNSB (Figura 1), localizado nos municípios de Bonito, Bodoquena, Jardim e Porto Murtinho, na porção centro-sul de Mato Grosso do Sul (21 $08^{\circ} 02^{\prime}$ " a $20^{\circ} 38^{\prime} 26^{\prime \prime} \mathrm{S}$ e $56^{\circ} 48^{\prime} 31^{\prime \prime}$ a $56^{\circ} 44^{\prime} 28^{\prime \prime}$ O), borda do Pantanal do Nabileque, é uma das áreas prioritárias para a conservação no Estado (MMA 2002). É composto de dois polígonos, com cerca de $77.000 \mathrm{ha}$, possuindo aproximadamente $300 \mathrm{~km}$ de comprimento (sentido norte-sul) e largura entre 20 e $50 \mathrm{~km}$. Geologicamente, a área é composta majoritariamente por rochas calcárias, o que favorece a formação de cavernas, sumidouros e ressurgências (Filho et al. 2004). A temperatura média anual oscila entre 20 e $22{ }^{\circ} \mathrm{C}$ e a precipitação 


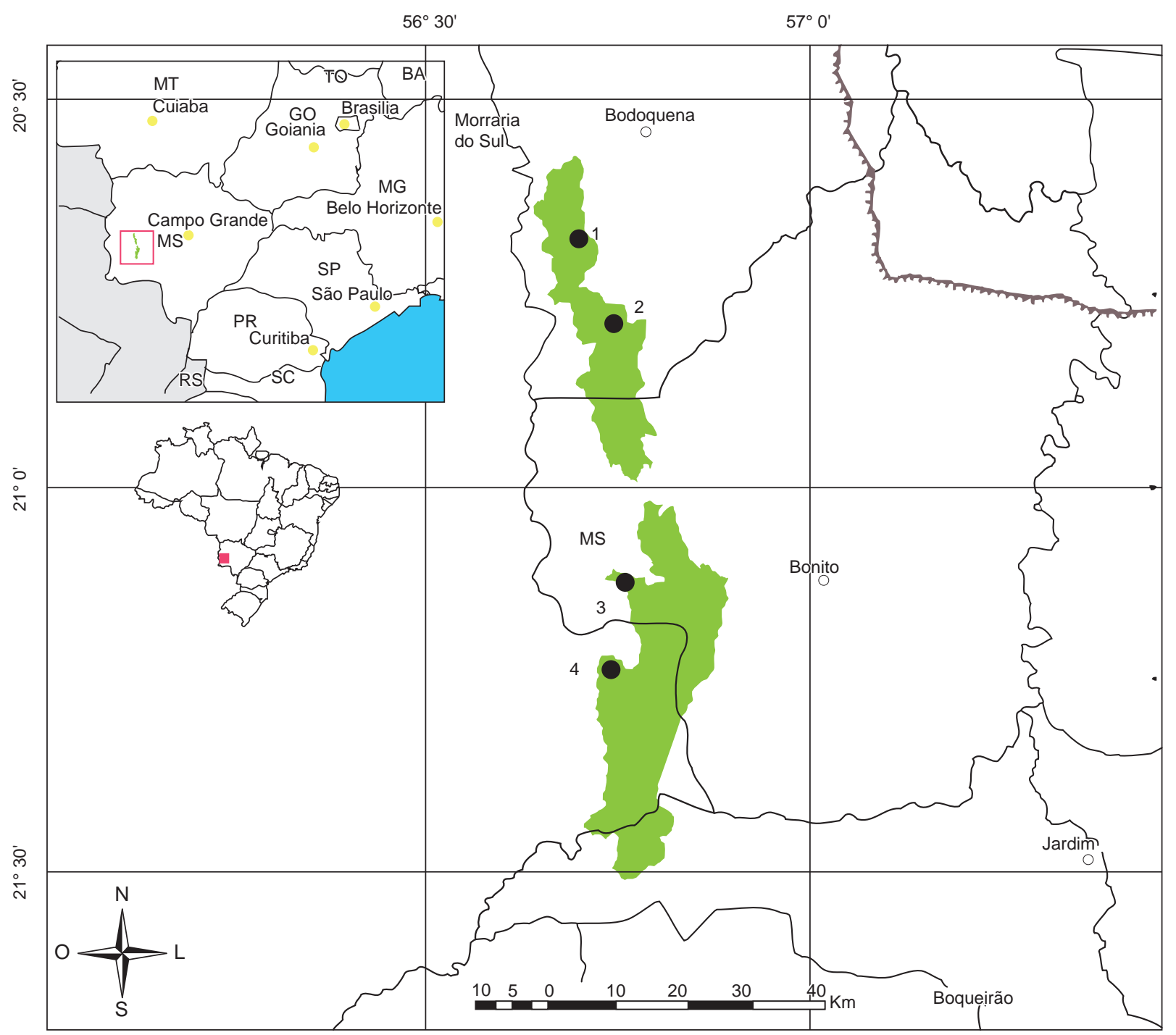

Figura 1. Mapa do Brasil com a localização do Parque Nacional da Serra da Bodoquena, estado de Mato Grosso do Sul (modificado de Ibama 2007). Os pontos referem-se aos quatro sítios de coleta, onde foram estabelecidos transectos para as amostragens (1: Fazenda Rancho Branco; 2: Fazenda Remanso; 3: Banhado do Perdido - Fazenda Laudejá; 4: Fazenda Harmonia).

Figure 1. Map of Brazil with the Serra da Bodoquena National Park, Mato Grosso do Sul State (modified from Ibama 2007). Points refer to the four collecting sites where transects were done for animal sampling (1: Fazenda Rancho Branco; 2: Fazenda Remanso; 3: Banhado do Perdido - Fazenda Laudejá; 4: Fazenda Harmonia).

média anual entre 1300 e $1700 \mathrm{~mm}$. As maiores precipitações pluviométricas ocorrem entre os meses de outubro e abril, com períodos de seca entre maio e setembro. As altitudes variam entre 450 e $800 \mathrm{~m}$ (Figura 2a), com predominância de matas estacionais semideciduais e matas estacionais semideciduais aluviais (Figura 2b), destacandose plantas como angico (Anadenanthera sp.), aroeira (Myracroduon urundeuva), capitão-do-campo (Terminalia argentea), gonçaloalves (Astronium fraxinifolium), caraguatá (Bromelia balansae), pau-terra-folha-larga (Qualea grandiflora), pau-terra-folha-miúda (Qualea parviflora), lixeira (Curatella americana) e diversas espécies de Gramineae e Cyperaceae nos campos e áreas alagadas (Alvarenga et al. 1982, Furtado et al. 1982, Boggiani \& Clemente 1999, Scremin-Dias et al. 1999).

As amostragens foram realizadas em duas etapas (30/08 a 10/09/2005 e 08 a 20/12/2005), abrangendo as estações seca e chuvosa. Foram determinados previamente quatro sítios de coleta (Figura 1), denominados de acordo com topônimos locais (Fazenda
Rancho Branco, Sítio 1; Fazenda Remanso, Sítio 2; Banhado do Perdido - Fazenda Laudejá, Sítio 3 e Fazenda Harmonia, Sítio 4). Esses sítios representam grande parte da variabilidade do PNSB em relevo, solo, hidrografia e vegetação abrangendo tanto áreas do Parque quanto o entrono. Em cada sítio, o número de pontos de amostragem variou de três a catorze, totalizando 29 pontos, sendo que cada ponto foi escolhido aleatoriamente dentro de cada sítio e com distância entre eles que permitisse uma independência dos dados amostrados (geralmente entre 2 e $5 \mathrm{~km}$ a distância entre cada ponto). Cada ponto foi caracterizado em macro-fisionomias e foram realizados em mata estacional semidecidual, mata estacional semidecidual aluvial (mata ciliar), cerrado aberto com afloramentos rochosos em áreas abertas, campo úmido com nascente (formado principalmente por capim-navalha, Cladium jamaicense; Cyperaceae), lagoas temporárias associadas a ressurgências, solo encharcado (brejo) em áreas de pastagem e lagoa artificial circundada por vegetação marginal (Figura 3.1 a 3.7). As amostragens no campo úmido de nascente 

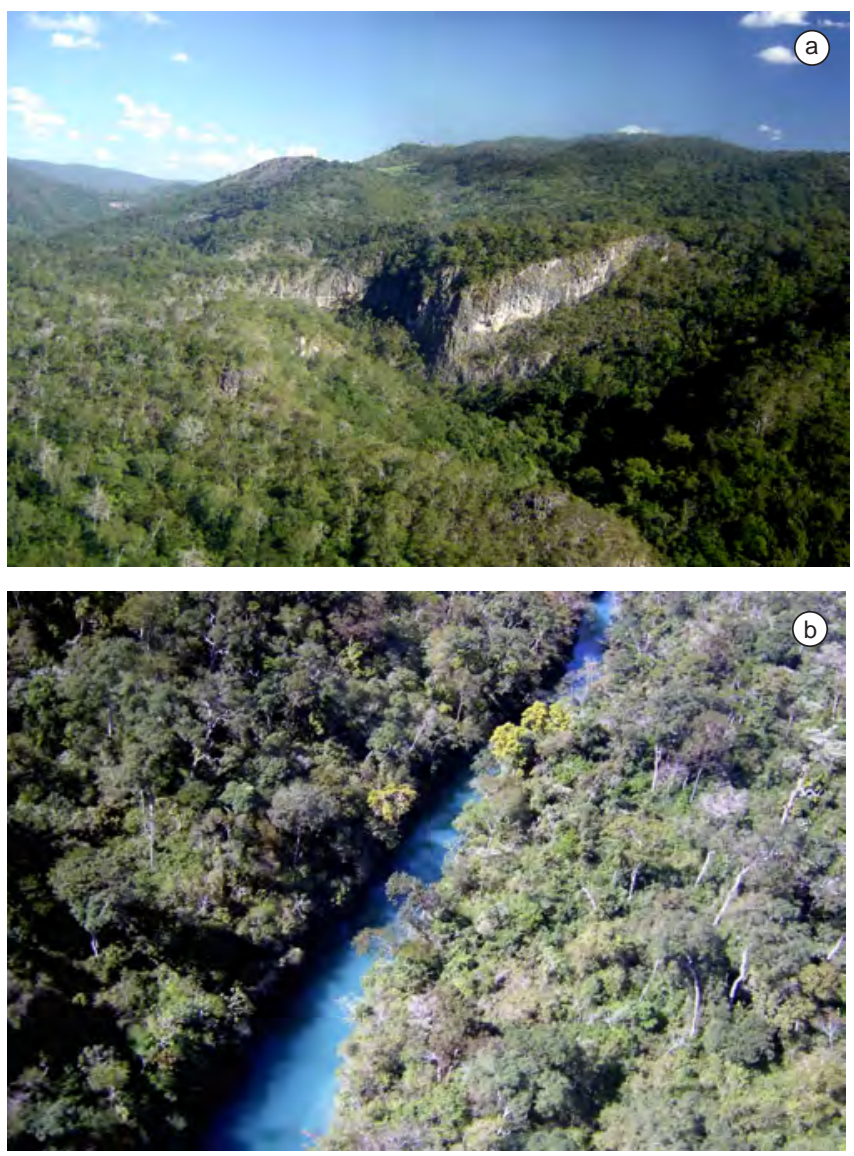

Figura 2. a) Vista panorâmica de parte do Parque Nacional da Serra da Bodoquena, estado de Mato Grosso do Sul, evidenciando o relevo montanhoso da área; b) Paisagem típica do Parque Nacional da Serra da Bodoquena, estado de Mato Grosso do Sul: floresta estacional semidecidual aluvial ao longo de rios com águas azuis, cuja tonalidade deve-se à grande quantidade de calcário em suspensão, originado do solo e das rochas. (Fotos: Otávio Froehlich).

Figure 2. a) Aerial view from the Serra da Bodoquena National Park, Mato Grosso do Sul State, showing the mountainous aspect of the area; b) Typical scenario from the Serra da Bodoquena National Park, Mato Grosso do Sul State: gallery forest along rivers with clear and blue waters caused by the high amount of calcareous in suspension originated from the soil and rocks. (Photos: Otávio Froehlich).

foram facilitadas devido a um incêndio ocorrido na área alguns dias antes das amostragens (Figura 3.1).

O inventário da herpetofauna consistiu em busca ativa limitada por tempo nos períodos diurno (9:00-14:00 horas) e noturno (18:0024:00 horas), através de transectos aleatórios (aproximadamente $2 \mathrm{~km}$ de extensão; faixa de largura variável), vasculhando-se os ambientes onde os animais habitualmente se abrigam (em cavidades de árvores, entre frestas de rochas, sob rochas e troncos, no solo, na serapilheira, nas moitas de bromélias e ao longo de vegetação marginal dos cursos d'água) (Heyer et al. 1994). Quando possível, foram efetuadas gravações dos cantos e fotos dos espécimes coletados para posterior auxílio na sua identificação. Registros oportunísticos também foram considerados, consistindo de amostragens por terceiros ou em locais fora dos sítios selecionados para as amostragens, mas na área abrangida pelo Parque. Para cada transecto percorrido, foram estimadas a riqueza e a abundância através de observação direta, onde o número de indivíduos de cada espécie foi registrado ao longo do tempo de amostragem em cada transecto. Para os anuros estes parâmetros também foram estimados através das vocalizações em períodos de atividade reprodutiva. Essa metodologia possibilitou a determinação das espécies mais representativas de cada ponto.

A expectativa de riqueza local de espécies foi estimada com base na abundância das espécies amostradas em cada um dos 29 pontos, através de curvas de rarefação (riqueza $x$ abundância). Para tanto, foi utilizado o índice não-paramétrico Jacknife 1 após 1000 aleatorizações dos dados pelo método Monte Carlo, usando-se o software EstimateS (Colwell 2005). As análises foram efetuadas apenas para anfíbios e lagartos. Serpentes não foram incluídas nas análises, uma vez que o tipo de inventário realizado não é o mais indicado para elaborar uma lista desses animais, o que poderia influenciar no comportamento da curva de rarefação. Uma vez que o Parque Nacional da Serra da Bodoquena pode ser considerado uma grande mancha de mata estacional semidecidual inserida na grande região da diagonal seca representada pelos biomas da Caatinga, Cerrado e Chaco (Prado \& Gibbs 1993, Spichiger et al. 2004, Morrone 2006), suspeita-se que a herpetofauna dessa área possa sofrer influência dessas formações na sua composição de espécies. Dessa maneira, informações sobre a herpetofauna da Caatinga (Vanzolini et al. 1980, Arzabe 1999, Rodrigues 2003), Cerrado (Strüssmann et al. 2000, Colli et al. 2002, Pavan \& Dixo 2002, 2004, Bastos et al. 2003, Brasileiro et al. 2005, Colli, 2005, Brandão et al. 2006, Uetanabaro et al. 2006, Brandão \& Araújo no prelo), Chaco (Bucher 1980, Norman 1994, de la Riva et al. 2000, Brusquetti \& Lavilla 2006) e serras do entorno do Pantanal sul-mato-grossense (Gordo \& Campos 2005) foram compiladas e comparadas com a registrada no presente trabalho através do Coeficiente de Similaridade de Jaccard (Magurran 2004). As análises de similaridade também não incluíram serpentes, pelo mesmo motivo exposto acima.

Os espécimes adultos de anfíbios e répteis foram coletados manualmente ou com auxílio de ganchos. Após a coleta, os animais foram anestesiados e mortos com xilocaína a 5\%, sendo em seguida fixados em formalina a $10 \%$ e conservados em álcool $70 \%$. Todos os animais coletados (Licença Ibama 175/2005) receberam etiquetas, contendo um registro individual e o local de coleta. Exemplarestestemunho foram depositados na Coleção Zoológica de Referência da Universidade Federal de Mato Grosso do Sul (ZUFMS) e na Coleção Herpetológica da Universidade de Brasília (CHUNB). Para a identificação dos répteis foram utilizadas as chaves de Peters \& Donoso-Barros (1970), Vanzolini (1986), Torres-Carvajal (2005) e o catálogo eletrônico para lagartos do cerrado de G. Colli \& L. O. Oliveira (http://www.unb.br/ib/zoo/grcolli/guia/guia.html). Anfíbios foram identificados com base em suas vocalizações e pela consulta a especialistas.

\section{Resultados}

Foram totalizadas 450 horas/homem de amostragem durante os períodos de coleta, registrando-se um total de 63 espécies (incluindo três registros oportunísticos), sendo 38 de anfíbios e 25 de répteis. A família de anfíbios mais representativa foi Hylidae (16 espécies) enquanto de répteis foi Colubridae (cinco espécies; Tabela 1). A distribuição das espécies não foi homogênea entre os ambientes amostrados. Rhinella scitula esteve associada às matas de galeria, Scinax squalirostris, Melanophryniscus fulvoguttatus e Leptodactylus jolyi foram encontradas predominantemente no campo úmido de nascente, Stenocercus caducus em locais com vegetação arbórea (mata estacional semidecidual) e Anolis meridionalis em cerrado aberto com afloramentos rochosos (Figura 3a-r). As espécies mais comuns e abundantes foram $R$. scitula, com >500 indivíduos encontrados nas matas estacionais semideciduais aluviais, Dendropsophus 

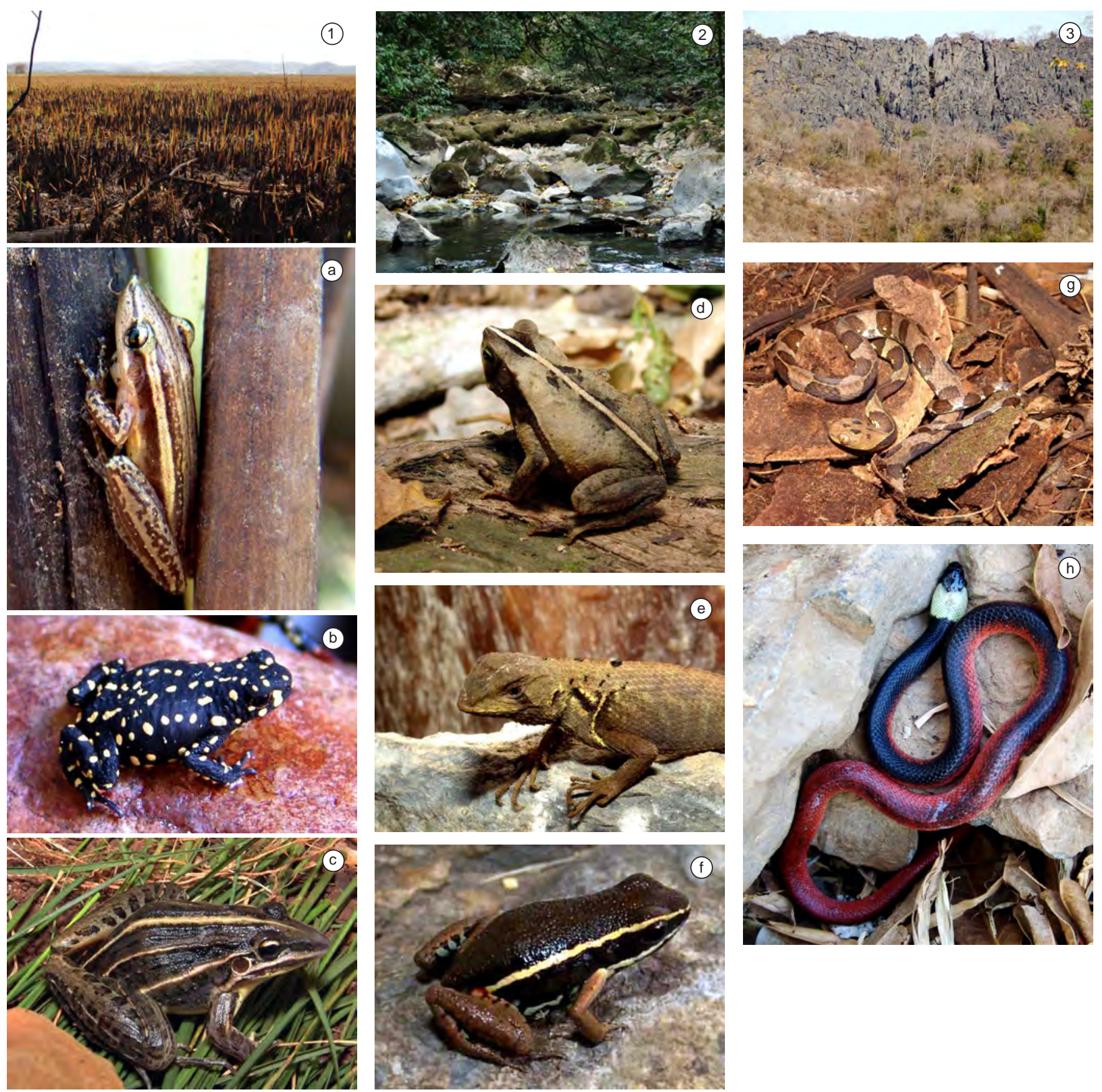

Figura 3. Alguns dos diversos ambientes de amostragem da herpetofauna do Parque Nacional da Serra da Bodoquena (incluindo áreas do entorno) e algumas das principais espécies de répteis e anfíbios associadas. Campo úmido com nascente após queimada 1) Scinax squalirostris (a), Melanophryniscus fulvoguttatus (b) e Leptodactylus jolyi (c); floresta estacional semidecidual aluvial 2) Rhinella scitulla (d), Stenocercus caducus (e) e Ameerega picta (f); floresta estacional decidual 3) Dipsas sp. (g) e Pseudoboa nigra (h); áreas abertas com afloramentos rochosos 4) Anolis meridionalis (i) e Tropidurus guarani (j); lagoa artificial circundada por vegetação marginal 5) Caiman latirostris (k), Phyllomedusa sauvagii (1) e Dendropsophus elianae (m); solo encharcado (brejo) em áreas de pastagem 6) Sibynomorphus mikanii (n), Leptodactylus podicipinus (o) e Liophis poecilogyrus (p); vegetação secundária de floresta 7) Colobosaura modesta (q) e Ameiva ameiva (r). (Fotos: Masao Uetanabaro).

Figure 3. Some sampled habitats from the Serra da Bodoquena National Park, including the surrounding plateau, and some reptile and amphibian species related. Burned wet field with headwaters 1) Scinax squalirostris (a), Melanophryniscus fulvoguttatus (b), and Leptodactylus jolyi (c); gallery forest 2) Rhinella scitulla (d), Stenocercus caducus (e), and Ameerega picta (f); dry forest (3): Dipsas sp. (g) and Pseudoboa nigra (h); open areas with exposed rocky soil 4) Anolis meridionalis (i) and Tropidurus guarani (j); artificial lagoon surrounded by vegetation 5) Caiman latirostris (k), Phyllomedusa sauvagii (1), and Dendropsophus elianae (m); pasture in flooding areas 6) Sibynomorphus mikanii (n), Leptodactylus podicipinus (o), and Liophis poecilogyrus (p); secondary forest 7) Colobosaura modesta (q) and Ameiva ameiva (r). (Photos: Masao Uetanabaro). 

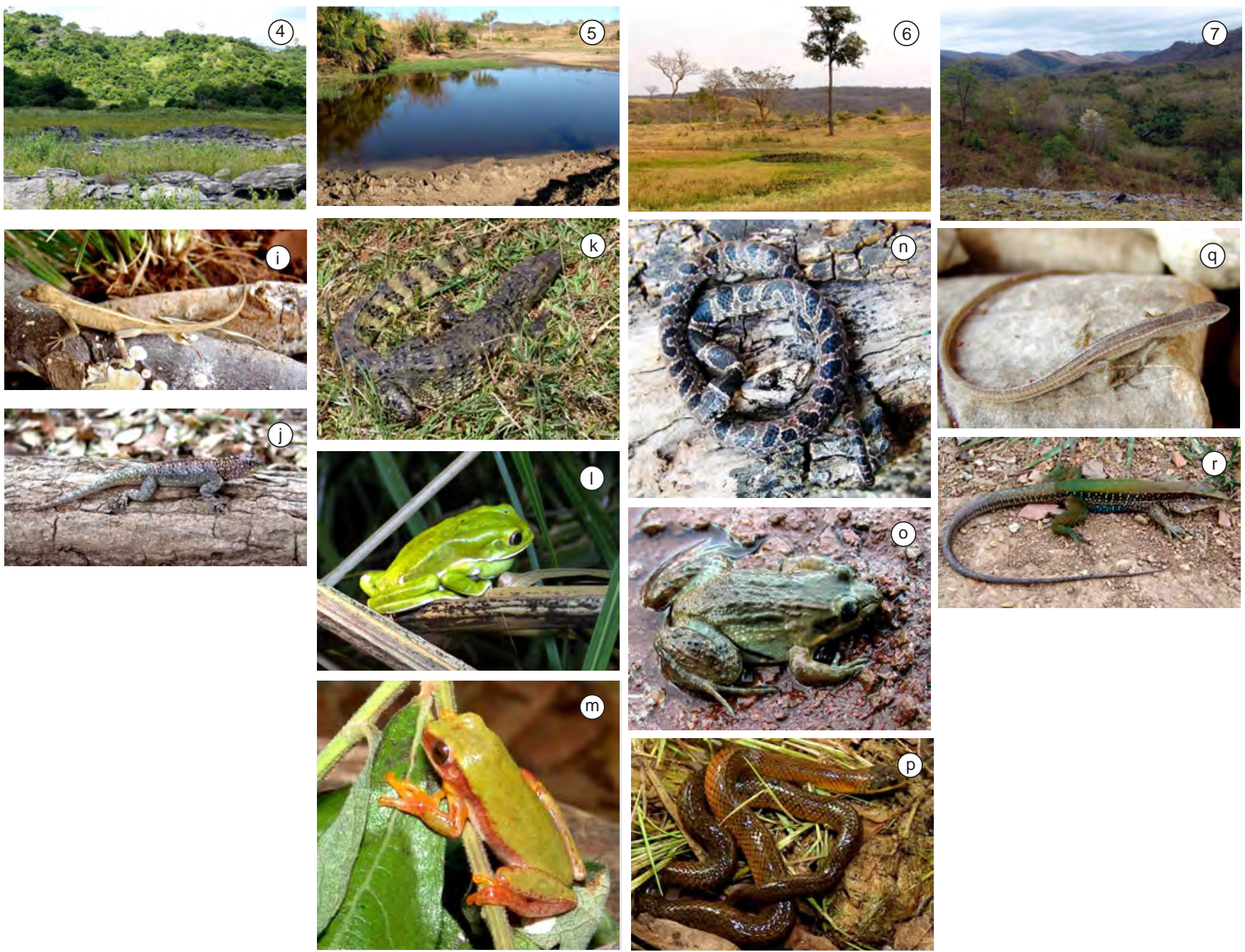

Figura 3. Alguns dos diversos ambientes de amostragem da herpetofauna do Parque Nacional da Serra da Bodoquena (incluindo áreas do entorno) e algumas das principais espécies de répteis e anfíbios associadas. Campo úmido com nascente após queimada 1) Scinax squalirostris (a), Melanophryniscus fulvoguttatus (b) e Leptodactylus jolyi (c); floresta estacional semidecidual aluvial 2) Rhinella scitulla (d), Stenocercus caducus (e) e Ameerega picta (f); floresta estacional decidual 3) Dipsas sp. (g) e Pseudoboa nigra (h); áreas abertas com afloramentos rochosos 4) Anolis meridionalis (i) e Tropidurus guarani (j); lagoa artificial circundada por vegetação marginal 5) Caiman latirostris (k), Phyllomedusa sauvagii (1) e Dendropsophus elianae (m); solo encharcado (brejo) em áreas de pastagem 6) Sibynomorphus mikanii (n), Leptodactylus podicipinus (o) e Liophis poecilogyrus (p); vegetação secundária de floresta 7) Colobosaura modesta (q) e Ameiva ameiva (r). (Fotos: Masao Uetanabaro).

Figure 3. Some sampled habitats from the Serra da Bodoquena National Park, including the surrounding plateau, and some reptile and amphibian species related. Burned wet field with headwaters 1) Scinax squalirostris (a), Melanophryniscus fulvoguttatus (b), and Leptodactylus jolyi (c); gallery forest 2) Rhinella scitulla (d), Stenocercus caducus (e), and Ameerega picta (f); dry forest (3): Dipsas sp. (g) and Pseudoboa nigra (h); open areas with exposed rocky soil 4) Anolis meridionalis (i) and Tropidurus guarani (j); artificial lagoon surrounded by vegetation 5) Caiman latirostris (k), Phyllomedusa sauvagii (1), and Dendropsophus elianae (m); pasture in flooding areas 6) Sibynomorphus mikanii (n), Leptodactylus podicipinus (o), and Liophis poecilogyrus (p); secondary forest 7) Colobosaura modesta (q) and Ameiva ameiva (r). (Photos: Masao Uetanabaro).

nanus (>300 indivíduos) nas lagoas com vegetação marginal e mais de 15 exemplares de Tropidurus cf. itambere registrados em vegetação aberta com afloramentos rochosos.

A curva de rarefação mostrou um rápido aumento do número de espécies com o aumento do tamanho amostral, tanto para répteis (Figura 4a) como para anfíbios (Figura 4b), sendo este crescimento mais acentuado para anfíbios, que também apresentou uma menor inclinação nos últimos pontos amostrados, podendo indicar uma possível estabilização ou aproximação do número real de espécies.

A herpetofauna do Parque Nacional da Serra da Bodoquena, quando comparada à encontrada nos biomas vizinhos, apresentou maior similaridade com o Cerrado, com variação de 31 a $46 \%$ para répteis (Figura 5a) e de 17 a $32 \%$ para anfíbios (Figura 5b). Todavia, ressalta-se a alta similaridade $(46 \%)$ entre a fauna de anfíbios do Parque e aquela amostrada em outras localidades no planalto do entorno do Pantanal sul-mato-grossense.

\section{Discussão}

A herpetofauna registrada para o Parque Nacional da Serra da Bodoquena supera em número de espécies (Anura $=37$, Gymnophiona $=1$, Reptilia $=25$ ) os registros anteriores disponíveis para a região (Strüssmann et al. 2000, Gordo \& Campos 2005). 
Tabela 1. Lista de espécies de anfíbios e répteis registradas para o Parque Nacional da Serra da Bodoquena, Mato Grosso do Sul, Brasil, entre agosto e dezembro/2005, considerando-se o período de ocorrência (S: seca; C: chuva) e os principais ambientes onde foram observadas.

Table 1. Checklist of amphibians and reptiles from the Serra da Bodoquena National Park, Mato Grosso do Sul State, central Brazil, recorded between August and December/2005, according to the season (S: dry; C: rainy) and main habitat types.

\begin{tabular}{|c|c|c|}
\hline Família/Espécies & Período & Principais ambientes de ocorrência \\
\hline \multicolumn{3}{|l|}{ BUFONIDAE } \\
\hline Chaunus sp. (gr. granulosus) & $\mathrm{S}, \mathrm{C}$ & lagoas temporárias associadas a ressurgências \\
\hline Chaunus schneideri & $\mathrm{S}, \mathrm{C}$ & $\begin{array}{l}\text { solo encharcado (brejo) em áreas de pastagem; floresta estacional semidecidual } \\
\text { aluvial }\end{array}$ \\
\hline Melanophryniscus fulvoguttatus & $\mathrm{S}, \mathrm{C}$ & campo úmido com nascente \\
\hline Rhinella scitula & $\mathrm{S}, \mathrm{C}$ & floresta estacional semidecidual aluvial \\
\hline \multicolumn{3}{|l|}{ DENDROBATIDAE } \\
\hline Ameerega picta & $\mathrm{S}, \mathrm{C}$ & floresta estacional semidecidual aluvial \\
\hline \multicolumn{3}{|l|}{ HYLIDAE } \\
\hline Dendropsophus nanus & $\mathrm{S}, \mathrm{C}$ & campo úmido com nascente, lagoa artificial circundada por vegetação marginal \\
\hline Dendropsophus minutus & $\mathrm{S}, \mathrm{C}$ & $\begin{array}{l}\text { solo encharcado (brejo) em áreas de pastagem; lagoas temporárias associadas a } \\
\text { ressurgências }\end{array}$ \\
\hline Dendropsophus elianae & $\mathrm{C}$ & lagoa artificial circundada por vegetação marginal \\
\hline Dendropsophus microcephalus & $\mathrm{C}$ & campo úmido com nascente, lagoa artificial circundada por vegetação marginal \\
\hline Dendropsophus cf. rubicundulus & $\mathrm{C}$ & lagoas temporárias associadas a ressurgências \\
\hline Hypsiboas punctatus & $\mathrm{C}$ & amostragem oportunística \\
\hline Hypsiboas raniceps & $\mathrm{S}, \mathrm{C}$ & campo úmido, açude com vegetação marginal \\
\hline Phyllomedusa azurea & $\mathrm{C}$ & lagoa artificial circundada por vegetação marginal \\
\hline Phyllomedusa sauvagii & $\mathrm{S}, \mathrm{C}$ & $\begin{array}{l}\text { solo encharcado (brejo) em áreas de pastagem, lagoa artificial circundada por } \\
\text { vegetação marginal }\end{array}$ \\
\hline Pseudis paradoxa & $\mathrm{S}, \mathrm{C}$ & lagoa artificial circundada por vegetação marginal \\
\hline Scinax cf. ruber & $\mathrm{C}$ & solo encharcado (brejo) em áreas de pastagem \\
\hline Scinax fuscovarius & $\mathrm{S}, \mathrm{C}$ & $\begin{array}{l}\text { floresta estacional semidecidual aluvial; solo encharcado (brejo) em áreas de pasta- } \\
\text { gem; lagoa artificial circundada por vegetação marginal }\end{array}$ \\
\hline Scinax nasicus & $\mathrm{C}$ & solo encharcado (brejo) em áreas de pastagem; campo úmido com nascente \\
\hline Scinax fuscomarginatus & $\mathrm{S}$ & campo úmido com nascente \\
\hline Scinax squalirostris & $\mathrm{S}, \mathrm{C}$ & campo úmido com nascente \\
\hline Trachycephalus venulosus & $\mathrm{S}, \mathrm{C}$ & $\begin{array}{l}\text { floresta estacional semidecidual aluvial; solo encharcado (brejo) em áreas de } \\
\text { pastagem }\end{array}$ \\
\hline \multicolumn{3}{|l|}{ LEPTODACTYLIDAE } \\
\hline Leptodactylus chaquensis & $\mathrm{S}, \mathrm{C}$ & lagoa artificial circundada por vegetação marginal \\
\hline Leptodactylus elenae & $\mathrm{C}$ & $\begin{array}{l}\text { lagoa artificial circundada por vegetação marginal; lagoas temporárias associadas } \\
\text { a ressurgências } \\
\text { campo úmido com nascente; lagoa artificial circundada por vegetação marginal }\end{array}$ \\
\hline Leptodactylus fuscus & $\mathrm{C}$ & \\
\hline Leptodactylus jolyi & $\mathrm{C}$ & campo úmido com nascente; solo encharcado (brejo) em áreas de pastagem \\
\hline Leptodactylus labyrinthicus & $\mathrm{C}$ & solo encharcado (brejo) em áreas de pastagem \\
\hline Leptodactylus mystacinus & $\mathrm{C}$ & solo encharcado (brejo) em áreas de pastagem \\
\hline Leptodactylus podicipinus & $\mathrm{S}, \mathrm{C}$ & $\begin{array}{l}\text { floresta estacional semidecidual aluvial; solo encharcado (brejo) em áreas de } \\
\text { pastagem }\end{array}$ \\
\hline Leptodactylus syphax & $\mathrm{S}, \mathrm{C}$ & floresta estacional semidecidual aluvial \\
\hline \multicolumn{3}{|l|}{ BRACHYCEPHALIDAE } \\
\hline Eleutherodactylus sp. & $\mathrm{C}$ & floresta estacional semidecidual aluvial \\
\hline \multicolumn{3}{|l|}{ LEIUPERIDAE } \\
\hline Eupemphix nattereri & $\mathrm{C}$ & amostragem oportunística \\
\hline Physalaemus albonotatus & $\mathrm{S}, \mathrm{C}$ & $\begin{array}{l}\text { floresta estacional semidecidual aluvial; lagoas temporárias associadas a ressurgên- } \\
\text { cias; lagoa artificial circundada por vegetação marginal }\end{array}$ \\
\hline Physalaemus cuvieri & $\mathrm{C}$ & $\begin{array}{l}\text { lagoa artificial circundada por vegetação marginal; vegetação secundária de } \\
\text { floresta }\end{array}$ \\
\hline Pseudopaludicola mystacalis & $\mathrm{C}$ & amostragem oportunística \\
\hline \multicolumn{3}{|l|}{ CYCLORAMPHIDAE } \\
\hline Odontophrynus americanus & $\mathrm{C}$ & lagoas temporárias associadas a ressurgências \\
\hline
\end{tabular}


Tabela 1. Continuação...

\begin{tabular}{|c|c|c|}
\hline Família/Espécies & Período & Principais ambientes de ocorrência \\
\hline \multicolumn{3}{|l|}{ MICROHYLIDAE } \\
\hline Elachistocleis cf. bicolor & $\mathrm{C}$ & floresta estacional semidecidual aluvial; campo úmido com nascente \\
\hline Chiasmocleis albopunctata & $\mathrm{C}$ & floresta estacional decidual \\
\hline \multicolumn{3}{|l|}{ CAECILIIDAE } \\
\hline Siphonops paulensis & $\mathrm{C}$ & floresta estacional semidecidual aluvial \\
\hline \multicolumn{3}{|l|}{ TESTUDINIDAE } \\
\hline Geochelone carbonaria & $\mathrm{C}$ & $\begin{array}{l}\text { floresta estacional semidecidual aluvial; solo encharcado (brejo) em áreas de } \\
\text { pastagem }\end{array}$ \\
\hline \multicolumn{3}{|l|}{ ALLIGATORIDAE } \\
\hline Caiman latirostris & $\mathrm{S}, \mathrm{C}$ & $\begin{array}{l}\text { lagoa artificial circundada por vegetação marginal; lagoas temporárias associadas } \\
\text { a ressurgências }\end{array}$ \\
\hline \multicolumn{3}{|l|}{ AMPHISBAENIDAE } \\
\hline Amphisbaena vermicularis & $\mathrm{S}$ & floresta estacional semidecidual aluvial \\
\hline \multicolumn{3}{|l|}{ POLYCHROTIDAE } \\
\hline Anolis meridionalis & $\mathrm{S}$ & áreas abertas com afloramento rochoso \\
\hline \multicolumn{3}{|l|}{ TROPIDURIDAE } \\
\hline Tropidurus guarani & $\mathrm{S}, \mathrm{C}$ & áreas abertas com afloramento rochoso; vegetação secundária de floresta \\
\hline Tropidurus cf. itambere & $\mathrm{S}, \mathrm{C}$ & áreas abertas com afloramento rochoso; vegetação secundária de floresta \\
\hline Stenocercus caducus & $\mathrm{C}$ & floresta estacional semidecidual aluvial; floresta estacional decidual \\
\hline \multicolumn{3}{|l|}{ GEKKONIDAE } \\
\hline Hemidactylus mabouya & $\mathrm{C}$ & Vegetação secundária de floresta \\
\hline Lygodactylus wetzli & $\mathrm{C}$ & clareira em floresta estacional semidecidual aluvial \\
\hline \multicolumn{3}{|l|}{ ANGUIDAE } \\
\hline Ophiodes striatus & $\mathrm{S}$ & lagoas temporárias associadas a ressurgências \\
\hline \multicolumn{3}{|l|}{ TEIIDAE } \\
\hline Ameiva ameiva & $\mathrm{S}, \mathrm{C}$ & $\begin{array}{l}\text { vegetação arbustiva em área de pastagem; floresta estacional decidual; áreas abertas } \\
\text { com afloramento rochoso; vegetação secundária de floresta }\end{array}$ \\
\hline Tupinambis merianae & $\mathrm{C}$ & floresta estacional semidecidual aluvial; vegetação arbustiva em área de pastagem \\
\hline \multicolumn{3}{|l|}{ GYMNOPHTALMIDAE } \\
\hline Cercosaura ocellata & S & campo úmido com nascente \\
\hline Colobosaura modesta & $\mathrm{S}$ & Vegetação secundária de floresta \\
\hline Micrablepharus maximilliani & $\mathrm{C}$ & áreas abertas com afloramento rochoso \\
\hline \multicolumn{3}{|l|}{ SCINCIDAE } \\
\hline Mabuya cf. frenata & $\mathrm{C}$ & floresta estacional semidecidual aluvial \\
\hline Mabuya guaporicola & S & campo úmido com nascente \\
\hline Mabuya cf. nigropunctata & $\mathrm{S}$ & floresta estacional semidecidual aluvial \\
\hline \multicolumn{3}{|l|}{ TYPHLOPIDAE } \\
\hline Typhlops sp. & S & solo encharcado (brejo) em áreas de pastagem \\
\hline \multicolumn{3}{|l|}{ COLUBRIDAE } \\
\hline Dipsas sp. & $\mathrm{C}$ & floresta estacional decidual \\
\hline Pseudoboa nigra & $\mathrm{S}, \mathrm{C}$ & floresta estacional decidual com curso d'água intermitente \\
\hline Liophis poecilogyrus & $\mathrm{S}, \mathrm{C}$ & solo encharcado (brejo) em áreas de pastagem \\
\hline Sibynomorphus mikanii & S & solo encharcado (brejo) em áreas de pastagem \\
\hline Waglerophis merremii & $\mathrm{S}$ & floresta estacional semidecidual aluvial \\
\hline \multicolumn{3}{|l|}{ VIPERIDAE } \\
\hline Crotalus durissus & $\mathrm{C}$ & floresta estacional semidecidual aluvial \\
\hline
\end{tabular}

Comparando-se as espécies registradas no presente estudo com aquelas amostradas por Strüssmann et al. (2000), verifica-se que somente 13 espécies de anuros e duas de répteis são comuns e podem ser consideradas generalistas quanto ao hábitat (e.g. Dendropsophus nanus, Scinax fuscovarius), de ampla distribuição geográfica (e.g. Crotalus durissus) ou que ocupam rapidamente áreas que sofreram perturbações antrópicas (e.g. Ameiva ameiva). Por outro lado, algu- mas espécies mais exigentes quanto ao hábitat, presentes em áreas mais restritas como nascentes com predominância de gramíneas, formação ciliar florestada ou afloramentos rochosos (e.g. Rhinella scitula e Tropidurus cf. itambere), foram registradas apenas neste presente trabalho.

No período chuvoso houve um aumento significativo de espécies de anfíbios anuros em relação ao período seco (20 para 37 espé- 

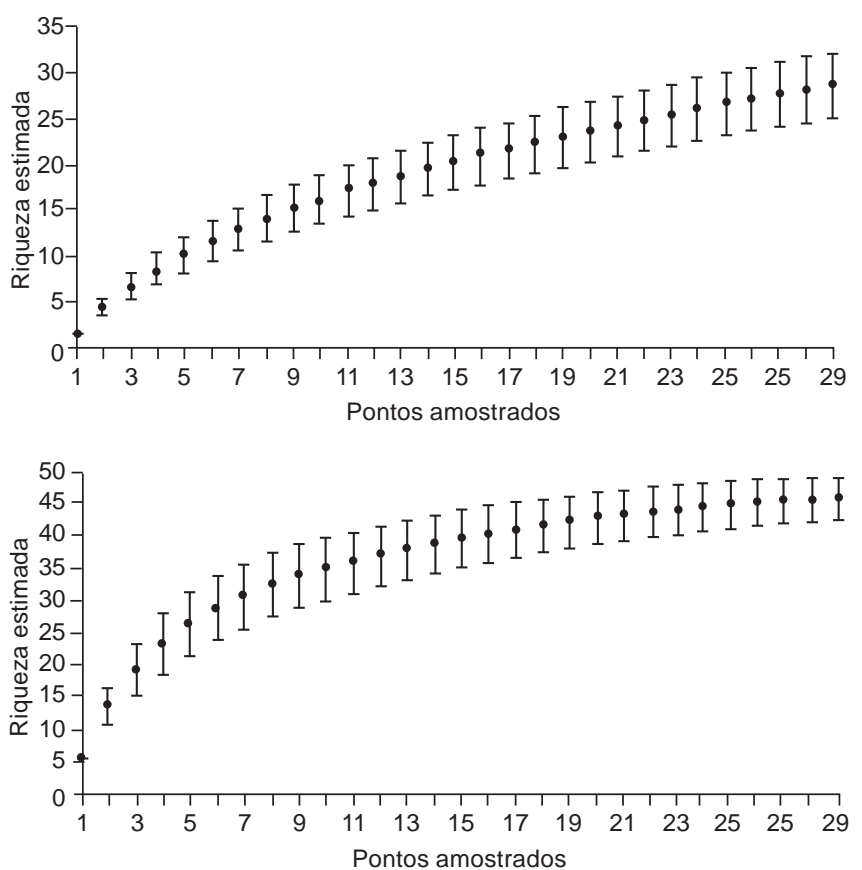

Figura 4. Curvas de rarefação para a) répteis (exceto serpentes) e b) anfíbios no Parque Nacional da Serra da Bodoquena, Mato Grosso do Sul, Brasil. A curva representa riqueza média estimada pelo método Jacknife 1 após 1000 aleatorizações das amostras de cada um dos 29 pontos amostrados e as barras verticais os respectivos desvios-padrão.

Figure 4. Rarefaction curves for a) reptiles (except snakes) and b) amphibians from the Serra da Bodoquena National Park, Mato Grosso do Sul State, central Brazil. Curves represent mean richness (bars denote standard deviations) estimated by Jacknife 1 method after 1,000 randomizations of the samples from the 29 sampled points.

cies), refletindo os padrões reprodutivos de várias espécies como Elachistocleis cf. bicolor, Trachycephalus venulosus, Eupemphix nattereri, Physalaemus albonotatus e Phyllomedusa sauvagii (Rodrigues et al. 2003, 2004, 2005). A relação entre o número de espécies observadas e o esforço empregado nas amostragens pode fornecer informações sobre a diversidade total da comunidade do Parque. Todavia, para nenhum dos grupos a assíntota foi alcançada, embora o esforço amostral pareça ter sido mais eficiente para os anfíbios.

As análises de similaridade demonstraram que a comunidade da herpetofauna do Parque Nacional da Serra da Bodoquena e entorno assemelhou-se com a do Cerrado, provavelmente porque a área está inserida em uma paisagem majoritariamente dominada por esse bioma. Geologicamente, a planície do Pantanal é limitada por planaltos, que são as áreas mais elevadas, denominadas localmente de serras, incluindo aquelas localizadas nas regiões de Maracajú (leste), Urucum-Amolar (oeste) e Bodoquena (sul) (Assine 2004). Nessas áreas, há um predomínio das florestas estacionais deciduais e semideciduais (Pott \& Pott 2003), o que pode explicar a similaridade da fauna de anfíbios do PNSB com aquela de outras regiões do entorno do Pantanal sul-mato-grossense, refletindo a importância dessas áreas para a zoogeografia local. Várias espécies foram comuns para a Serra da Bodoquena, Caatinga e Chaco, principalmente aquelas de áreas abertas e que por isso se beneficiam da paisagem de borda (Ameiva ameiva, Crotalus durissus, Chaunus schneideri, Dendropsophus minutus e Scinax fuscovarius, por exemplo). A influência chaquenha na comunidade de anfíbios e répteis da Serra da Bodoquena pode ser

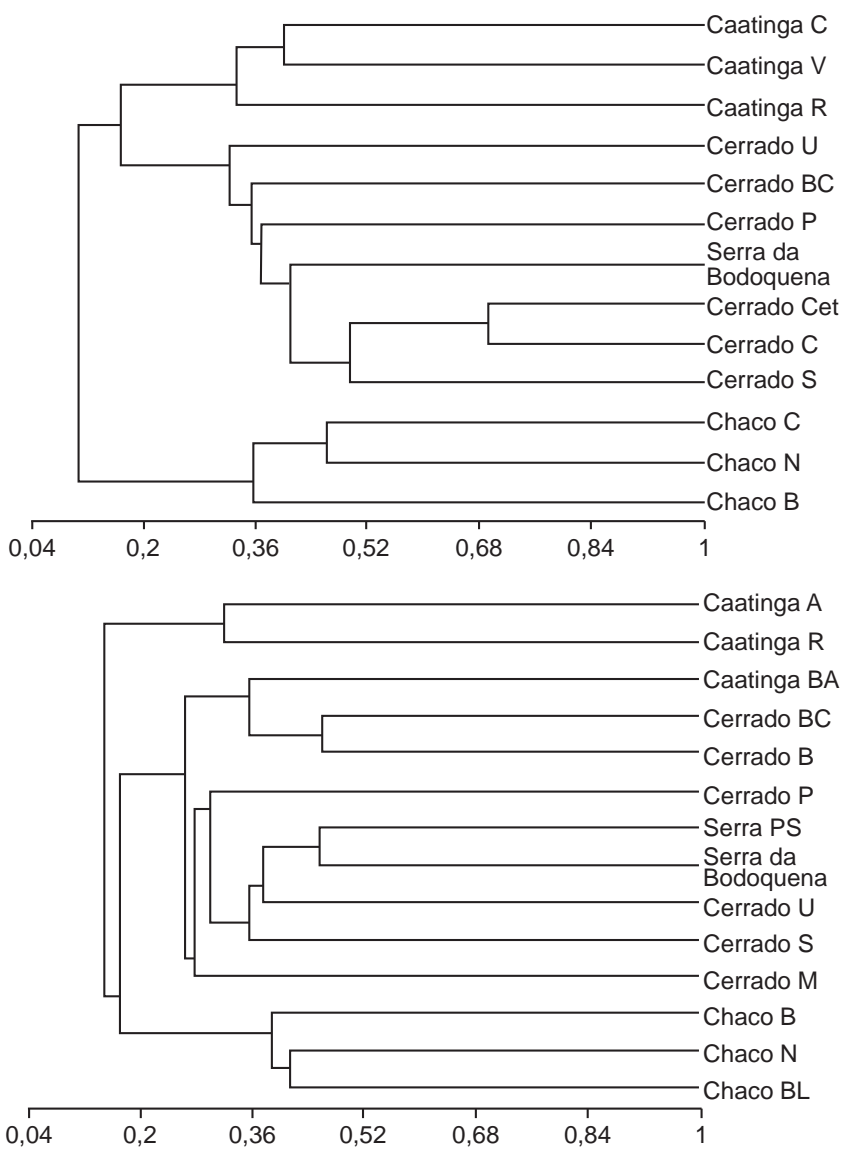

Figura 5. Dendrogramas de similaridade (Coeficiente de Similaridade de Jaccard), utilizando-se UPGMA como método de agrupamento, entre a fauna de a) répteis e b) anfíbios de várias localidades (incluindo o Parque Nacional da Serra da Bodoquena) representando os biomas Caatinga, Cerrado e Chaco (Caatinga A = Arzabe 1999, Caatinga $\mathrm{C}=$ Colli 2005, Caatinga $\mathrm{R}=$ Rodrigues 2003, Caatinga V = Vanzolini et al. 1980, Cerrado B = Bastos et al. 2003, Cerrado $\mathrm{BA}=$ Brandão \& Araújo no prelo, Cerrado $\mathrm{BC}=$ Brandão et al. 2006, Cerrado $\mathrm{C}=$ Colli 2005, Cerrado Cet $=$ Colli et al. 2002, Cerrado $\mathrm{M}=$ Brasileiro et al. 2005, Cerrado P = Pavan \& Dixo 2002-2004; Cerrado S = Strüssmann 2000, Cerrado U = Uetanabaro et al. 2006, Chaco B = Bucher 1980, Chaco BL = Brusquetti \& Lavilla 2006, Chaco C = Colli 2005, Chaco $\mathrm{N}=$ Norman 1994, Serra PS = Gordo \& Campos 2005).

Figure 5. Dendrogram for the cluster analysis (Coefficient of Jaccard and cluster analysis by UPGMA) of several a) reptile and b) amphibian assemblages (including the Serra da Bodoquena National Park), representing Caatinga, Cerrado, and Chaco biomes (Caatinga A = Arzabe 1999, Caatinga $\mathrm{C}=$ Colli 2005, Caatinga $\mathrm{R}=$ Rodrigues 2003, Caatinga $\mathrm{V}=$ Vanzolini et al . 1980, Cerrado B = Bastos et al. 2003, Cerrado BA = Brandão \& Araújo no prelo, Cerrado BC $=$ Brandão et al. 2006, Cerrado $C=$ Colli 2005, Cerrado Cet $=$ Colli et al. 2002, Cerrado $\mathrm{M}=$ Brasileiro et al. 2005, Cerrado $\mathrm{P}=$ Pavan \& Dixo 2002-2004; Cerrado $S=$ Strüssmann 2000, Cerrado U = Uetanabaro et al. 2006, Chaco B = Bucher 1980, Chaco BL = Brusquetti \& Lavilla 2006, Chaco C = Colli 2005, Chaco N = Norman 1994, Serra PS = Gordo \& Campos 2005)

verificada pelo registro de diversas espécies incluindo Phyllomedusa sauvagii, Leptodactylus elenae, L. chaquensis e Melanophryniscus fulvoguttatus (Brusquetti \& Lavilla 2006). Entre os répteis, esse padrão pôde ser retratado por Lygodactylus wetzeli, cuja distribuição geográfica é restrita à Serra da Bodoquena, ao maciço do Urucum (MS) e ao chaco da porção oriental da Bolívia (Peters \& Donoso-Barros 1970, Werneck \& Colli, 2006). Por outro lado, foram registradas 
no PNSB espécies que não ocorrem no Chaco nem na Caatinga, sendo particularmente marcante para anuros (e.g. Dendropsophus microcephalus, Ameerega picta e Rhinella scitula). De fato, estudos recentes têm demonstrado a relevante proporção de espécies endêmicas de anuros na fauna do Cerrado e a ocorrência de espécies de distribuição restrita (Diniz-Filho et al. 2004, 2006).

A herpetofauna amostrada não apresentou nenhum representante inserido nas listas oficiais nacionais de ameaçadas de extinção (Ibama 2007). Entretanto, listados nos apêndices I (todo o comércio internacional proibido) e II (comércio internacional monitorado e regulado) da CITES estão os répteis Geochelone carbonaria (II), Tupinambis merianae (II) e Caiman latirostris (I) e o anfíbio Ameerega picta (II) (CITES 2007). Deve ser ressaltado que caça, fogo, erosão, assoreamento e desmatamento são fatores e eventos relativamente comuns na região e prática corriqueira dentro do Parque antes do local ser transformado em Unidade de Conservação, o que significa que ameaças externas devem ser monitoradas.

Considerando-se a diversidade de hábitats da área (ver Tabela 1) e a curva de rarefação de anfíbios e répteis, provavelmente o número de espécies deverá aumentar com a realização de novos inventários na região. A metodologia utilizada e a duração das etapas de coletas para amostrarem répteis podem não ser consideradas eficientes porque esses animais geralmente apresentam maior mobilidade e conseqüentemente uma maior capacidade de fuga do que os anuros. Além disso, muitos representantes da herpetofauna possuem camuflagem extremamente eficiente, o que demandaria mais tempo amostral e a combinação de diversos métodos de captura. Sugere-se, dentre outras metodologias de coleta, o uso intenso de armadilhas de interceptação e queda (Cechin \& Martins 2000) em próximos estudos. Agregar novas informações sobre a herpetofauna da Serra da Bodoquena é fundamental para apoiar ações de conservação e de planejamento do Parque Nacional da Serra da Bodoquena.

\section{Agradecimentos}

Os autores são gratos ao Ibama (Diretoria de Ecossistemas e Sede do Parque Nacional da Serra da Bodoquena), Exército Brasileiro e proprietários das fazendas pelo apoio logístico durante o estudo. Autorização de licença para captura dos animais foi concedida pelo Ibama (processo no 02001.004999/05-02; licença no 175/2005). Cynthia P. Prado e um revisor anônimo contribuíram de maneira significativa com comentários e sugestões.

\section{Referências Bibliográficas}

ALVARENGA, S.M., BRASIL, A.E. \& DEL'ARCO, D.M. 1982. Geomorfologia. In IBGE, Levantamento de Recursos Naturais, 28, Campo Grande, Folha SF-21. Rio de Janeiro, p. 125-184.

ARZABE, C. 1999. Reproductive activity patterns in two different altitudinal sites within the Brazilian Caatinga. Rev. bras. Zool. 16(3):851-864.

ASSINE, M.L. 2004. A bacia sedimentar do pantanal Mato-Grossense. In Geologia do Continente Sul-Americano: evolução da obra de Fernando Flávio Marques de Almeida (V. Mantesso-Neto, A. Bartorelli, C.D.R. Carneiro \& B.B. Brito-Neves, orgs.). Beca, São Paulo, p. 61-74.

BASTOS R.P., MOTTA J.A.O, LIMA L.P \& GUIMARÃES L.D. 2003. Anfíbios da Floresta Nacional de Silvânia, Estado de Goiás. Stylo Gráfica e Editora, Goiânia.

BOGGIANI, P.C. \& CLEMENTE, J. 1999. A questão do Licenciamento Ambiental de Empreendimentos Turísticos no Planalto da Bodoquena Mato Grosso do Sul. Rev. Geogr. 2(9):29-40.

BRASILEIRO, C.A., SAWAYA, R.J., KIEFER, M.C. \&. MARTINS, M. 2005. Amphibians of an open Cerrado fragment in southeastern Brazil. Biota Neotrop. 2(5):http://www.biotaneotropica.org.br/v5n2/pt/ abstract?article+BN00405022005.
BRANDÃO, R.A. \& ARAÚJO, A.F.B. 2001. A herpetofauna associada às matas de galeria no Distrito Federal. In Caracterização e Recuperação de Matas de Galeria (J.F. Ribeiro, C.E.L. Fonseca \& J.C. Sousa-Silva, eds.). Embrapa, Planaltina, p. 561-604.

BRANDÃO, R.A \& ARAÚJO, A.F.B. no prelo. Changes on anuran richness and abundance due to flooding and habitat insularization at Serra da Mesa hydroelectric dam, central Brazil. Biotropica.

BRANDÃO, R.A., SEBBEN, A. \& ZERBINI, G.J. 2006. A herpetofauna da APA de Cafuringa. In APA de Cafuringa: A Última Fronteira Natural do Distrito Federal (P.B. Netto, V.V. Mecenas \& E.S. Cardoso, eds.). Secretaria de Meio Ambiente e Recursos Hídricos, Brasília, p. 241-248.

BRUSQUETTI, F. \& LAVILLA, E.O. 2006. Lista comentada de los anfibios de Paraguay. Cuadernos de Herpetología 20(2):3-79.

BUCHER, H. 1980. Ecología de la fauna Chaqueña. Una revisón. Ecosur 7(4):111-159.

CABRERA, M.A. 1995. Comparative composition of turtle species in four natural regions of the Chacoan domain, South America. An. Mus. Hist. Nat. Valparaíso 23(1):41-52.

CARAMASCHI, U. \& NIEMEYER, H. 2003. Nova espécie do complexo de Bufo margaritifer (Laurenti, 1768) do Estado do Mato Grosso do Sul, Brasil (Amphibia, Anura, Bufonidae). Bol. Mus. Nac. Zoologia 501(1):1-16.

CECHIN, S.Z. \& MARTINS, M. 2000. Eficiência de armadilhas de queda (pitfall traps) em amostragens de anfíbios e répteis no Brasil. Rev. Bras. Zool. 17(3):729-740.

CITES. 2007. Convention on International Trade in Endangered Species of Wild Fauna and Flora. Disponível em: http://www.cites.org/; acessado em 22/03/2007.

COLLI, G.R., BASTOS, R.P. \& ARAÚJO, A.F.B. 2002. The character and dynamics of the Cerrado herpetofauna. In The Cerrados of Brazil: Ecology and Natural History of a Neotropical Savanna. (P.S. Oliveira \& R.J. Marquis, eds.). Columbia University Press, New York, p. 223-241.

COLLI, G.R. 2005. As origens e a diversificação da herpetofauna do Cerrado. In Cerrado: Ecologia, Biodiversidade e Conservação. (A. Scariot, J.C. Souza-Silva \& J.M. Felfili, eds.). Ministério do Meio Ambiente, Brasília, p. 247-264.

COLWELL, R.K. 2005. EstimateS: Statistic estimation of species richness and shared species from samples. Version 7.5. Disponível em: <http://viceroy.eeb.uconn.edu/estimates>.

COUTINHO, L. M. 1978. O conceito de cerrado. Revta. Brasil. Bot. 1(1):17-23.

De La RIVA, I., KÖHLER, J., LÖTTERS, S. \& REICHLE, S. 2000. Ten years of research on Bolivian amphibians: updated checklist, distribution, taxonomic problems, literature and iconography. Rev. Esp. Herp. 14:19-164.

DINIZ-FILHO, J.A., BINI, L.M. VIEIRA, C.M., SOUZA, M.C., BASTOS, R.P. BRANDÃO, D. \& OLIVEIRA, L.G. 2004. Spatial patterns in species richness and priority areas for conservation of anurans in the Cerrado region, Central Brazil. Amphibia-Reptilia 25:63-75.

DINIZ-FILHO, J.A., BINI, L.M., PINTO, M.P., RANGEL, T.F.L.V.B, CARVALHO, P. \& BASTOS, R.P. 2006. Anuran species richness, complementarity and conservation conflicts in Brazilian Cerrado. Acta Oecologica 29:9-15.

DUELLMAN, W.E. 1999. Distribution patterns of amphibians in South America. In Patterns of Distribution of Amphibians (W.E. Duellman, ed.). The Johns Hopkins University Press, Baltimore and London, p. 255-327.

EITEN, G. 1972. The cerrado vegetation of Brazil. Bot. Review 38(2):201-341.

FILHO, W.S., KARMANN, I. \& BOGGIANI, P.C. 2004. Paisagens cársticas da Serra da Bodoquena (MS). In Geologia do Continente Sul-Americano: evolução da obra de Fernando Flávio Marques de Almeida (V. MantessoNeto, A. Bartorelli, C.D.R. Carneiro \& B.B. Brito-Neves, orgs.). Beca, São Paulo, p. 423-433.

FURTADO, P.P., GUIMARÃES J.G. \& FONSAR, B.C. 1982. Vegetação estudo fitogeográfico. In IBGE, Levantamento de Recursos Naturais, 28, Campo Grande, Folha SF-21. Rio de Janeiro, p. 281-316. 
GHEDINI, R.C. 2004. Diversidade e estratificação de anuros em lagoas na Serra da Bodoquena, município de Bodoquena, Mato Grosso do Sul. Dissertação de Mestrado, Universidade Federal de Mato Grosso do Sul, Campo Grande.

GORDO, M. \& CAMPOS, Z.M.S. 2005. Anuros das serras de entorno do Pantanal Sul. Embrapa Pantanal, Séries Documentos 78:1-21.

HEYER, W.R., DONNELLY, M.A., McDIARMID, R.W., HAYEK, L.C. \& FOSTER, M.S. 1994. Measuring ands monitoring biological diversity. Standard methods for Amphibians. Smithsonian Institution Press, Washington.

IBAMA, 2007. Lista nacional das espécies da fauna brasileira ameaçadas de extinção. Ministério do Meio Ambiente. Disponível em: http://www.mma. gov.br/port/sbf/fauna/index.cfm; (acessado em 22/03/2007).

MAGURRAN, A.E. 2004. Measuring biological diversity. Oxford, Blackwell.

MILES, L., NEWTON, A.C., DEFRIES, R.S., RAVILIOUS, C., MAY, I., BLYTH, S., KAPOS, V. \& GORDON, J.E. 2006. A global overview of the conservation status of tropical dry forests. J. Biogeogr. 33:491-505.

MMA. 2002. Avaliação e identificação de áreas e ações prioritárias para a conservação, utilização sustentável e repartição dos benefícios da biodiversidade nos biomas brasileiros. MMA/SBF, Brasília.

MORRONE, J.J. 2006. Biogeographic areas and transition zones of latin america and the caribbean islands based on panbiogeographic and cladistic analyses of the entomofauna. Annu. Rev. Entomol. 51:467-494.

MORRONE, J.J., MAZZUCCONI, S.A. \& BACHMANN, A.O. 2004. Distributional patterns of Chacoan water bugs (Heteroptera: Belostomatidae, Corixidae, Micronectidae and Gerridae). Hydrobiologia 523:159-173.

NAPOLI, M.F. \& CARAMASCHI, U., 2000. Description and variation of a new Brazilian species of the Hyla rubicundula group (Anura, Hylidae). Alytes 17(3-4):165-184.

NORMAN, D.R. 1994. Anfibios y reptiles del Chaco paraguayo, Tomo 1. Amphibians and Reptiles of the Paraguayan Chaco, Volume 1. Private printing, San José, Costa Rica.

PAVAN, D. \& DIXO, M. 2002-2004. A herpetofauna da área de influência do reservatório da Usina Hidrelétrica Luís Eduardo Magalhães, Palmas, TO. Humanitas 4/6:13-30.

PETERS, J.A. \& DONOSO-BARROS, R. 1970. Catalogue of the Neotropical Squamata. Part II. Lizards and Amphisbaenians. Bull. U.S. Natl. Mus. 297(2):1-293.

POTT, A. \& POTT, V.J. 2003. Espécies de fragmentos florestais em Mato Grosso do Sul. In Fragmentação Florestal e Alternativas de Desenvolvimento Rural na Região Centro-Oeste (R.B. Costa, org.). UCDB, MS, p. 26-52.

PRADO, D.E. \& GIBBS, P.E. 1993. Patterns of species distributions in the dry seasonal forests of South América. Ann. Mo. Bot. Gard. 80:902-927.

PRIMACK, R.B. 2002. Essentials of Conservation Biology. Sinauer, Sunderland.

RODRIGUES, D.J. 2001. Estratégias reprodutivas de anurofauna em áreas de inundações temporárias na Serra da Bodoquena, Mato Grosso do Sul. Dissertação de Mestrado, Universidade Federal de Mato Grosso do Sul, Campo Grande.

RODRIGUES, D.J., LOPES, F.S. \& UETANABARO, M. 2003. Padrão reprodutivo de Elachistocleis cf. bicolor, Valenciennes, 1838 (Amphibia: Anura) na Serra da Bodoquena, MS. Iheringia, Série Zoologia, 93(4):365-371.

RODRIGUES, D.J., UETANABARO, M. \& LOPES, F.S. 2004. Reproductive strategies of Physalaemus nattereri (Steindachner, 1863) and P. albonotatus (Steindachner, 1862) at Serra da Bodoquena, State of Mato Grosso do Sul, Brazil. Rev. Esp. Herp. 18:63-73.
RODRIGUES, D.J., UETANABARO, M. \& LOPES, F.S. 2005. Reproductive patterns of Trachicephalus venulosus (Laurenti, 1768) and Scinax fuscovarius (Lutz, 1925) from the Cerrado, Central, Brazil. J. Nat. Hist. 39(35):3217-3226.

RODRIGUES, M.T. 2003. Herpetofauna da Caatinga. In Biodiversidade, ecologia e conservação da Caatinga. (M. Tabarelli \& J.M.C. Silva, eds.). Universidade Federal de Pernambuco, Recife, p. 181-236.

SCREMIN-DIAS, E., POTT, V.J., SOUZA, P.R. \& HORA, R.C. 1999. Nos Jardins Submersos da Bodoquena: Guia para Identificação das Plantas Aquáticas de Bonito e Região de Bonito/MS. Editora da Universidade Federal de Mato Grosso do Sul, Campo Grande.

SILVA, J.F., FARIÑAS, M.R., FELFILI, J.M. \& KLINK, C.A. 2006. Spatial heterogeneity, land use and conservation in the cerrado region of Brazil. J. Biogeogr. 33:536-548.

SBH - SOCIEDADE BRASILEIRA DE HERPETOLOGIA. 2005a. Lista de espécies de anfíbios do Brasil. Sociedade Brasileira de Herpetologia (SBH). Disponível em: http://www.sbherpetologia.org.br/checklist/ anfibios.htm; (acessado em 22/03/2007).

SBH - SOCIEDADE BRASILEIRA DE HERPETOLOGIA. 2005b. Lista de espécies de répteis do Brasil. Sociedade Brasileira de Herpetologia (SBH). Disponível em: http://www2.sbherpetologia.org.br/checklist/repteis.htm; (acessado em 22/03/2007)

SOUZA, F.L. 2005. Geographical distribution patterns of South American side-necked turtles (Chelidae), with emphasis on Brazilian species. Rev. Esp. Herp. 19:33-46.

SPICHIGER, R. CALENGE, C. \& BISE, B. 2004. Geographical zonation in the Neotropics of tree species characteristic of the Paraguay-Parana Basin. J. Biogeogr. 31:1489-1501.

STRÜSSMANN, C., PRADO, C.P.A., UETANABARO, M. \& FERREIRA, V. L. 2000. Levantamento de anfíbios e répteis de localidades selecionadas na porção sul da planície alagada do Pantanal e Cerrado do entorno, Mato Grosso do Sul, Brasil. In Uma avaliação ecológica dos ecossistemas aquáticos do Pantanal, Mato Grosso do Sul, Brasil (P.W. Willink, B. Chernoff, L.E. Alonso, J.R. Montambault \& R. Lourival, eds.). Conservation International. Washington, DC, p. 219-223.

TORRES-CARVAJAL, O. 2005. A new species of Stenocercus (Squamata, Iguanidae) from central-western Brazil with a key to Brazilian Stenocercus. Phyllomedusa 4(2):123-132.

UETANABARO, M., GUIMARÃES, L.D., BÉDA, A.F., LANDGREF FILHO, P., PRADO, C.P.A., BASTOS, R.P. \& ÁVILA, R.W. 2006. Inventário da herpetofauna do Complexo Aporé-Sucuriú. In Biodiversidade do Complexo Jauru, subsídios à conservação e manejo do Cerrado (T.C.S. Pagotto \& P.R. Souza, orgs.). Editora UFMS, Campo Grande, p. $105-112$.

VANZOLINI, P.E. 1986. Addenda and corrigenda to the Catalogue of the Neotropical Squamata. Smithsonian Herpetol. Inform. Serv. 70:1-26.

VANZOLINI, P.E. 1988. Distributional patterns of South American Lizards. In Proceedings of a Workshop on Neotropical Distribution Patterns (P.E. Vanzolini \& W.R. Heyer, eds.). Academia Brasileira de Ciências, Rio de Janeiro, p.317-342.

VANZOLINI, P.E., RAMOS-COSTA, A.M.M., \& VITT, L.J. 1980. Répteis da Caatinga. Academia Brasileira de Ciências. Rio de Janeiro.

VELOSO, H.P., FILHO, A.L.R.R. \& LIMA, J.C.A. 1991. Classificação da vegetação brasileira, adaptada a um sistema universal. IBGE, Rio de Janeiro.

WERNECK, F.P \& COLLI, G.R. 2006. The lizard assemblage from Seasonally Dry Tropical Forest enclaves in the Cerrado biome, Brazil, and its association with the Pleistocenic Arc. J. Biogeogr. 33:1983-1992. 
